\title{
Effect of variation of exposure to airborne chlorobenzene on internal exposure and concentrations of urinary metabolite
}

\author{
Shinji Kumagai, Ichiro Matsunaga
}

\begin{abstract}
Objectives-This study aimed to develop a physiologically based pharmacokinetic model for chlorobenzene and to investigate the effect of variation in exposure to chlorobenzene on the chlorobenzene concentration in blood and the urinary concentration of 4-chlorocatechol.
\end{abstract}

Methods-A physiologically based pharmacokinetic model was developed and the simulated results of urinary 4-chlorocatechol concentrations were compared with the values found in experiments and field surveys. The area under the chlorobenzene concentration-time curve in blood (CBBauc) was selected as the measure of internal exposure related to the chronic effect of chlorobenzene. The maximum one-hour time weighted average value of chlorobenzene concentration in blood (CBBmax) was chosen as the measure of internal exposure related to the acute effect of chlorobenzene. The total amount of urinary 4-chlorocatechol (TOTCC) and that excreted during the last four hours (CC(4-8)) or two hours (CC(6-8)) of exposure as well as that excreted during two hours on the next morning (CC(22-24)) were used to represent concentrations of urinary metabolites. The effects of variation of the one-hour time weighted averages of airborne chlorobenzene exposure (CBAs) on the internal exposures and the concentrations of urinary metabolites were investigated with the pharmacokinetic model.

Results-The comparison of the simulated results with the observed data showed that the pharmacokinetic model can be used to estimate the urinary concentrations of 4-chlorocatechol. The CBBauc and TOTCC were not affected by changes in both the geometric SD (GSD) of CBAs or the variations in CBAs. The CBBmax varied with changes in both the GSD and CBAs. The CC(4-8) and $C C(6-8)$ did not vary with the GSD, but these concentrations were affected by the change in the CBAs. Although there was little effect of the GSD and CBAs on the CC(22-24), this value highly reflected the exposure over the preceding days. Conclusion-To protect workers from the chronic effect of chlorobenzene, it may be sufficient to control the daily average exposure. To protect from the acute effect, however, the short term exposure must be controlled as well. The values of
CC(4-8) and CC(6-8) were acceptable for estimating daily average exposure, but the CC(22-24) was not.

(Occup Environ Med 1995;52:65-70)

Keywords: chlorobenzene; 4-chlorocatechol; pharmacokinetic model

Chlorobenzene is a chemical widely used as an organic solvent, a chemical intermediate, and a heat transfer medium. It is toxic to the liver and kidney of animals and also has an acute effect on the central nervous system. ${ }^{1-3}$ Chlorobenzene is metabolised to 4-chlorocatechol (4-CC), $o-, m$ - and $p$-chlorophenols, and 4-chlorophenylmercapturic acid in humans..$^{4.7}$ Ogata et al found linear correlations between airborne exposure and urinary 4-CC and $p$ chlorophenol in an experimental study of humans. ${ }^{4}$ Yoshida et $a l^{6}$ and Kumagai and Matsunaga $^{7}$ also found similar results with workers exposed to chlorobenzene.

In general, the airborne exposures vary with time in workplaces. Previously, we showed that urinary 4-CC varied with the within day variation of the airborne exposure to chlorobenzene. ${ }^{7}$ Thus, the concentration of urinary 4-CC may not be appropriate as an index of daily average exposure when the variation in airborne exposure is high. Also, internal exposures, such as the chlorobenzene concentration in blood, can change with the variation in airborne exposure even if the daily average exposure is fixed. Although it is not clear whether the toxicity of chlorobenzene is due to the parent chemical or its metabolites, the chlorobenzene concentration in blood is considered to be closely related to the toxicity. Consequently, it is important for industrial hygienists to clarify how the variation in airborne exposure acts on the internal exposures.

The physiologically based pharmacokinetic model has been developed to simulate uptake, distribution, metabolism, and elimination of organic solvents. ${ }^{815}$ Although such a model requires much information including ventilation rate, cardiac output, metabolic rate, and tissue to blood partition coefficients, the internal exposure and urinary metabolite can be estimated by inputting the appropriate scenario of airborne exposure into the model. In this paper, we developed a physiologically based pharmacokinetic model for chlorobenzene and investigated how variation in airborne exposure affects the concentrations of chlorobenzene in blood and 4-CC in urine. 


\section{Methods}

DESCRIPTION OF THE MODEL

Figure 1 shows the diagram of our model. Table 1 summarises the parameters in the model.

The body is considered to consist of five groups of tissue for distribution of chlorobenzene (fig 1): the lung, blood vessel rich tissues containing the brain, heart, and kidney, a group of tissues containing muscles and skin that have low perfusion rates, fatty tissues, and an organ of metabolism, the liver. The volume of each tissue group was determined by multiplying the body weight by the relative percentage of the tissue group, which was calculated from the equations described by Fiserova-Bergerova and Hughes ${ }^{16}$ (table 1). Partition coefficients for chlorobenzene were $30.8 \mathrm{blood} / \mathrm{air}, 4.1$ water/air, and 3763 oil/air. ${ }^{17}$ Tissue/blood partition coefficients were calculated according to the equations proposed by Droz et al ${ }^{10}$ (table 1).

Alveolar ventilation at rest was taken from the data shown by Guyton ${ }^{18}$ and cardiac output from Stahl ${ }^{19}$ (table 1). At a physical workload of $40 \mathrm{~W}$ alveolar ventilation was assumed to be 2.6 times and cardiac output 1.6 times the resting values on the basis of linear relations between these physiological functions and workload as shown by Ástrand. ${ }^{20}$ The blood flow to each tissue group was determined by multiplying the cardiac output by the relative percentage of flow to each tissue (table 1). The relative percentage values at rest were calculated from the data shown by Fiserova-Bergerova and Hughes ${ }^{16}$ and at $40 \mathrm{~W}$ from Åstrand. ${ }^{20}$

It was assumed that metabolism of chlorobenzene occurs only in the liver and can be described by the "well stirred" model. ${ }^{21}$ Sullivan et al found the apparent half life of pulmonary chlorobenzene elimination in rats after inhalation exposure..$^{22}$ With the elimination constant and physiological parameters in rats, the hepatic intrinsic clearance was calculated to be $5700 \mathrm{ml} / \mathrm{h}$. The hepatic intrinsic clearance in humans was estimated to be $350 \mathrm{l} / \mathrm{h}$ (60-70 $\mathrm{kg}$ body weight) based on assumptions that the Michaelis constant $(\mathrm{Km})$ value is fixed between species and the

Table 1 Simulated parameters for humans

\begin{tabular}{|c|c|c|c|c|}
\hline \multirow[b]{2}{*}{ Tissue } & \multirow[b]{2}{*}{ Volume (I) } & \multicolumn{2}{|l|}{ Blood flow (I/h) } & \multirow[b]{2}{*}{$\lambda t i s / b / s$} \\
\hline & & Rest (OW) & Working (40W) & \\
\hline $\begin{array}{l}\text { Lung } \\
\text { Blood vessel rich } \\
\text { Muscles } \\
\text { Fatty } \\
\text { Liver }\end{array}$ & $\begin{array}{l}\mathrm{VL}^{\star} \\
0.067 \times \mathrm{BW} \\
0.491 \times \mathrm{BW} \\
0 \cdot 149 \times \mathrm{BW} \\
0.025 \times \mathrm{BW}\end{array}$ & $\begin{array}{l}\mathrm{Q}(0) \\
0.47 \times \mathrm{Q}(0) \dagger \\
0.24 \times \mathrm{Q}(0) \dagger \\
0.05 \times \mathrm{Q}(0) \dagger \\
0.24 \times \mathrm{Q}(0) \dagger\end{array}$ & $\begin{array}{l}\mathrm{Q}(40) \\
0.32 \times \mathrm{Q}(40) \ddagger \\
0.47 \times \mathrm{Q}(40) \ddagger \\
0.06 \times \mathrm{Q}(40) \ddagger \\
0.15 \times \mathrm{Q}(40) \ddagger\end{array}$ & $\begin{array}{c}3.6 \\
1.8 \\
86 \\
3.6\end{array}$ \\
\hline
\end{tabular}

Parameters: $\mathrm{Q}(0)=11.2 \times \mathrm{BW}^{0.81}$; $\mathrm{Av}(0)=0.7 \times 19.9 \times \mathrm{BW}^{0.74} \| ; \mathrm{Q}(40)=1.6 \times \mathrm{Q}(0)^{\star \star}$; Av (40) $=2.6 \times$ Av (0) $\star \star \star$; Hepatic intrinsic clearance $=350 \mathrm{Vhtt}$; Proportion of $4 \mathrm{CC}$ in total amount of urinary metabolites $=35 \%$; Urinary excretion constant of $4 \mathrm{CC}=0.315 \mathrm{~h}$. \#.

${ }^{*} \mathrm{VL}=$ functional residual capacity + (volume of artrial blood) $\times \lambda$ (blood/air) + (lung tissue volume) $\times i$. (tissue/air) by Fiserova-Bergerova et al..$^{15}$

†Fiserova-Bergerova and Hughes. ${ }^{10}$

The values were calculated based on the data by $A$ strand. ${ }^{20}$

$\delta \lambda$ tissue/blood were calculated by the equations proposed by Droz et al. ${ }^{10}$

TCardiac output $(\mathrm{l} / \mathrm{h})$ by Stahl. ${ }^{19}$

Alveolar ventilation $(\mathrm{l} / \mathrm{h})$ by Guyton. ${ }^{18}$

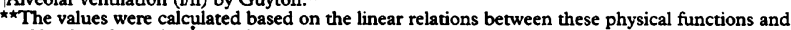
workload as shown by Âstrand. ${ }^{20}$

HThe value was estimated from the experimental data in rats by Sullivan et al. ${ }^{22}$

\#Ogata et al. ${ }^{*}$

$\mathrm{BW}=$ body weight $(\mathrm{kg})$

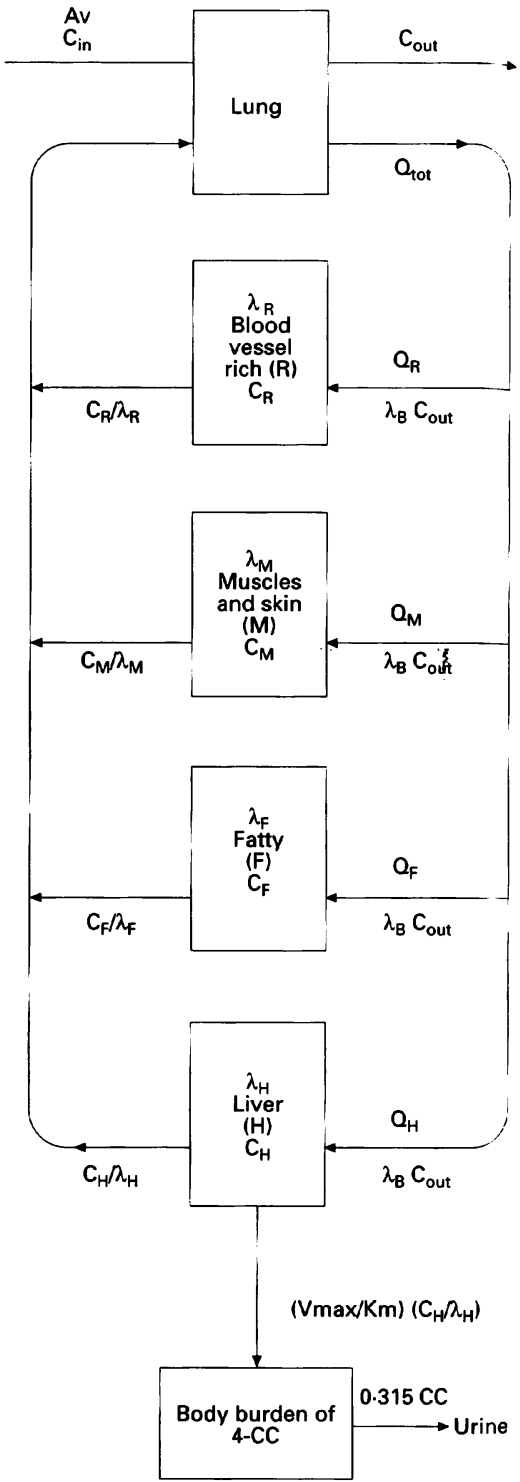

Figure 1 Diagram of the physiologically based pharmacokinetic model used to simulate the pattern of distribution of chlorobenzene in the body and urinary excretion of 4-CC. $V_{x}=$ volume of tissue group $X$ (1); $C_{x}=$ chlorobenzene concentration in tissue group $X(\mu g / l) ;$ $C_{i n}=$ chlorobenzene concentration in inhalation air $(\mu g / l)$; $C_{\text {our }}=$ chlorobenzene concentration in exhalation air ( $\mu \mathrm{g} / l) ; \lambda_{x}=$ tissuelblood partition coefficient in tissue group $X ; \lambda_{B}=$ bloodlair partition coefficient; $A_{0}=$ alveolar ventilation (l/h); $Q_{\text {tor }}=$ cardiac output (l/h); $Q_{x}=$ rate of blood flow to tissue group $X(\mathrm{l} / \mathrm{h}) ; V_{\max }=$ maximum enzymatic reaction rate $(\mu g / h) ; K_{m}=$ Michaelis constant $(\mu g / l)$.

maximum enzymatic reaction rate (Vmax) is linear to the 0.7 power of body weight. The proportion of 4-CC in all metabolites of chlorobenzene was assumed to be $35 \%$ (as chlorobenzene) so that the total amount of urinary 4-CC (as chlorobenzene) was close to 
$26.5 \%$ of the total amount of chlorobenzene passing through the lungs, which was based on the study by Ogata et al. ${ }^{4}$ The urinary elimination rate of 4-CC was assumed to be linear to the body burden. The urinary elimination constant of 4-CC was determined to be $0 \cdot 315 / \mathrm{h}$ according to the urinary excretion curve after inhalation exposure to 10 and $50 \mathrm{ppm}$ by human volunteers. ${ }^{4}$ We expressed the urinary 4-CC concentration relative to creatinine excretion, assuming that the urinary elimination rate of creatinine is $1.5 \mathrm{~g} /$ day in a human of $60 \mathrm{~kg}$ body weight and is a linear function of the volume of the muscle group of tissues. ${ }^{10}$

\section{COMPUTER SIMULATION}

The simultaneous differential equations describing the kinetics of chlorobenzene and 4-CC are as follows:

$$
\begin{aligned}
& \text { Lung } \\
& \mathrm{V}_{\mathrm{L}}\left(\mathrm{dC}_{\text {out }} / \mathrm{dt}\right)=\mathrm{AvC}_{\text {in }}+\mathrm{Q}_{\mathrm{M}} \mathrm{C}_{\mathrm{M}} / \lambda_{\mathrm{M}}+ \\
& \mathrm{Q}_{\mathrm{F}} \mathrm{C}_{\mathrm{F}} / \lambda_{\mathrm{F}}+\mathrm{Q}_{\mathrm{R}} \mathrm{C}_{\mathrm{R}} / \lambda_{\mathrm{R}}+\mathrm{Q}_{\mathrm{H}} \mathrm{C}_{\mathrm{H}} / \lambda_{\mathrm{H}}- \\
& Q_{\text {tot }} \lambda_{B} C_{\text {out }}-Q_{L} C_{\text {out }} \\
& \text { Liver } \\
& \mathrm{V}_{\mathrm{H}}\left(\mathrm{dC}_{\mathrm{H}} / \mathrm{dt}\right)=\mathrm{Q}_{\mathrm{H}} \lambda_{\mathrm{B}} \mathrm{C}_{\text {out }}- \\
& \left(\mathrm{Q}_{\mathrm{H}}+\operatorname{Vmax} / \mathrm{Km}\right)\left(\mathrm{C}_{\mathrm{H}} / \hat{\lambda}_{\mathrm{H}}\right) \\
& \text { Blood vessel rich } \\
& V_{R}\left(d C_{R} / d t\right)=Q_{R} \lambda_{B} C_{\text {out }}-Q_{R} C_{R} / \lambda_{R}
\end{aligned}
$$

Equations for muscle and fatty tissues are similar to that for blood vessel rich tissues.

Metabolism and excretion $\mathrm{dCC} / \mathrm{dt}=0.35(\mathrm{Vmax} / \mathrm{Km})$

$$
\left(\mathrm{C}_{\mathrm{H}} / \lambda_{\mathrm{H}}\right)-0.315 \mathrm{CC}
$$

Figure 1 explains the symbols in these equations. The differential equations were solved with a software package developed by Yamaoka, ${ }^{23}$ and were run on an NEC personal computer PC9801FA (NEC, Tokyo).

COMPARISON WITH OBSERVED DATA

To check the appropriateness of our model, the simulated concentrations of urinary 4-CC were compared with values found in experimental and field studies.

\section{Experimental data}

Urinary 4-CC concentrations were simulated with an exposure of $10 \mathrm{ppm}$ for three hours in the morning and for four hours in the afternoon with a break of one hour in between. The simulated results were compared with the human experimental results reported by Ogata et al. ${ }^{4}$ Because the mean minute ventilation of the human volunteers was reported to be $8.491 / \mathrm{min}$, alveolar ventilation of

Table 2 Three sets of seven $1 h$ TWAs of exposure to airborne chlorobenzene

\begin{tabular}{lcc}
\hline \multicolumn{2}{l}{ Variation of $1 \mathrm{hTWAs}$} \\
\hline GSD = $1.5(\mathrm{ppm})$ & $G S D=2.0(\mathrm{ppm})$ & GSD $=3.0(\mathrm{ppm})$ \\
\hline 5.1 & 3.0 & 1.2 \\
6.8 & 4.7 & 2.6 \\
7.8 & 6.1 & 3.9 \\
9.3 & 8.2 & 6.2 \\
11.0 & 10.8 & 9.8 \\
12.8 & 14.2 & 14.8 \\
16.9 & 22.7 & 31.1 \\
\hline
\end{tabular}

$5.94 \mathrm{l} / \mathrm{min}$ was introduced by multiplying the minute ventilation by 0.7 . The body weight was assumed to be $60 \mathrm{~kg}$, which is the average for Japanese men.

Field survey data

Previously, we measured consecutive onehour time weighted averages (TWAs) of chlorobenzene concentration in air (CBAs) and urinary 4-CC concentrations over full shifts (0800-1700) on Tuesday and Wednesday in workers $A$ (60 kg body weight) and $B(69 \mathrm{~kg}){ }^{7}$ The urinary $4-\mathrm{CC}$ concentrations caused by the exposure to chlorobenzene in the workplace were simulated based on the following assumptions. (1) The body burdens of chlorobenzene and 4-CC were zero on Monday morning. (2) Daily average exposure concentrations of chlorobenzene on Monday were assumed to be $17 \mathrm{ppm}$ for worker A and $13 \mathrm{ppm}$ for worker B. These values were estimated from urinary 4-CC concentrations on Tuesday morning (ju\$t before the workshift), because the relation between daily average exposure and urinary 4-CC concentration on the morning of the next day had been taken in our field survey (unpublished data). (3) Because consecutive CBAs were measured over full shifts on Tuesday and Wednesday in the two workers, the urinary 4-CC concentrations were simulated based on the scenarios of observed exposure. (4) The physical workload was $40 \mathrm{~W}$ during working hours and $0 \mathrm{~W}$ at the noon break and after the working hours. These values were measured in the workplace with calorie counters combined with an accelerometer (Kenz Calorie Counter, Suzuken, Nagoya, Japan). ${ }^{24}$

EFFECT OF VARIATION IN AIRBORNE EXPOSURE ON INTERNAL EXPOSURE AND

CONCENTRATIONS OF URINARY METABOLITES

We assumed that the airborne exposure varied in a log normal manner, so three sets of seven CBAs for three hours in the morning and four hours in the afternoon were selected (table 2). The arithmetic mean in each set was $10 \mathrm{ppm}$ and the geometric SDs (GSDs) were $1 \cdot 5,2 \cdot 0$, and 3.0 , which represent low, moderate, and high variations. ${ }^{25}$ The CBAs at the noon break and after working hours were $0 \mathrm{ppm}$. The physical workload was assumed to be $40 \mathrm{~W}$ during working hours and $0 \mathrm{~W}$ at the noon break and after working hours.

The area under the chlorobenzene concentration-time curve in blood (CBBauc) was selected as the measure of internal exposure that might be related to the chronic effect of chlorobenzene. The CBBauc was defined as:

$$
\mathrm{CBBauc}=\int_{0}^{\infty} \mathrm{CBB}(\mathrm{t}) \mathrm{dt} \text {. }
$$

where $\mathrm{CBB}(\mathrm{t})$ is chlorobenzene concentration in blood at time $t$. The maximum one-hour TWA value of chlorobenzene concentration in blood (CBBmax) was chosen as the measure of internal exposure that might be connected with the acute effect of chlorobenzene. 
Table 3 Comparison of simulated results with experimental values

\begin{tabular}{llll}
\hline & $\begin{array}{l}\text { CC(4-8) } \\
\text { (mg/g creatinine) }\end{array}$ & \multicolumn{1}{c}{$\begin{array}{l}\text { Excretion ratio } \\
\text { (\%) }\end{array}$} \\
\hline Simulation & 51.9 & 59.4 & 26.5 \\
Experimentt & 56.7 & 65.6 & 26.5
\end{tabular}

* Ratio of urinary 4-CC (as chlorobenzene) to the total amoun of chlorobenzene passed through the lungs.

of chlorobenzen

The total amount of urinary 4-CC (TOTCC), the 4-CC concentration in urine excreted during the last four hours of exposure (CC(4-8)), that during the last two hours of exposure $(\mathrm{CC}(6-8))$, and that during two hours the next morning (CC(22-24)) were selected as being representative of the concentration of urinary metabolites.

Simulation for the first exposure day was repeated 200 times. In each simulation, the seven CBAs were permutated at random by a generator of random numbers in a personal computer. Finally, the mean and coefficient of variation (CV) of the internal exposure and the concentration of urinary metabolites among the 200 trials were calculated. In workplaces, the internal exposure and concentration of urinary metabolites are considered to be affected by the exposure on the previous days and weeks. With our model, the body burdens of chlorobenzene and 4-CC were simulated based on the weekly schedule of five working days and two days holiday, and these burdens were estimated to reach steady state on or after the third week. Consequently; simulation on Thursday in a steady state week was also carried out.

\section{Results}

COMPARISON WITH OBSERVED DATA

Table 3 and fig 2 show the simulated and human experimental results of urinary 4-CC. The CC(4-8) was estimated to be 51.9 and the $\mathrm{CC}(6-8) \quad 59.4 \mathrm{mg} / \mathrm{g}$ creatinine, which agreed well with the experimental results. The simulated urinary 4-CC excretion curve after the exposure was very c'ose to the experimental one (fig 2).

Figures 3 and 4 show the results of the simulation and the field study. For worker B (fig 4), although the simulated concentrations of urinary 4-CC were about half of the corresponding values found in the first half of the shift, the agreement was within $15 \%$ over the last four hours. For worker A (fig 3), all estimated values except one were within $20 \%$ of the values found over the last four hours.

EFFECT OF VARIATION IN AIRBORNE EXPOSURE ON INTERNAL EXPOSURE

Table 4 lists the means and CVs of CBBauc among the 200 trials. The means of CBBauc were $3.01 \mathrm{mg} \mathrm{h} / \mathrm{h}$, and these values were fixed regardless of the change in the GSD of CBAs. Because the CVs of CBBauc were $<0.01$, the CBBauc value of each trial was almost never

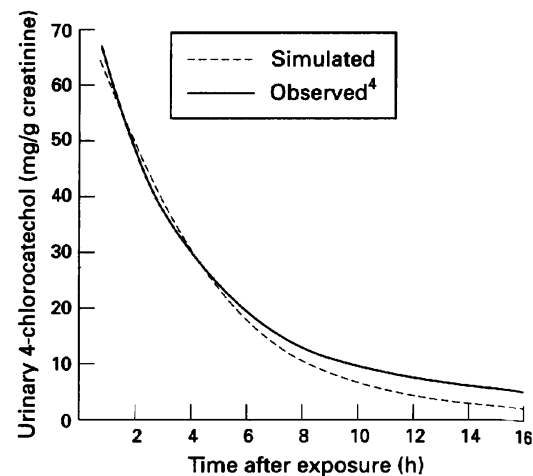

Figure 2 Comparison between simulated and observed urinary excretion curves of 4-CC after exposure to chlorobenzene at 10ppm.

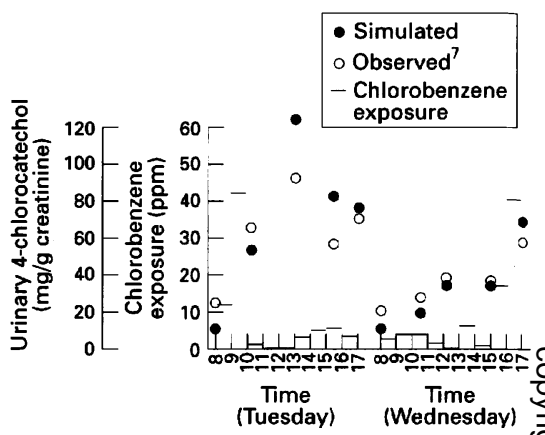

Figure 3 Comparison between simulated and observed values of urinary 4-CC in worker $A$

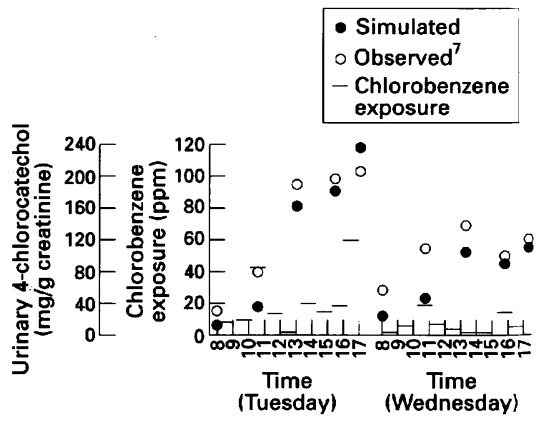

Figure 4 Comparison between simulated and observed values of urinary 4-CC in worker $B$.

Table 4 Effect of variation of airborne chlorobenzene exposure on internal exposure (CBBauc) *

\begin{tabular}{lll}
\hline \multirow{2}{*}{$\begin{array}{lll}\text { Airbome exposure } \\
\text { variation (GSD) }\end{array}$} & \multicolumn{2}{l}{$C B B a u c(m g . h / l)$} \\
\cline { 2 - 3 } & Mean & $C V$ \\
\hline 1.5 & 3.01 & $>0.01$ \\
2.0 & 3.01 & $>0.01$ \\
3.0 & 3.01 & $>0.01$ \\
\hline *Area under chlorobenzene & concentration-time curve in
\end{tabular}
blood. 
Table 5 Effect of variation of airborme chlorobenzene exposure on internal exposure (CBBmax)*

\begin{tabular}{lcc}
\hline \multirow{2}{*}{$\begin{array}{l}\text { Airborne exposure } \\
\text { variation (GSD) }\end{array}$} & \multicolumn{2}{c}{$C B B \max (\mathrm{mg} / \mathrm{l})$} \\
\cline { 2 - 3 } Mean & $C V$ \\
\hline First exposure day: & 0.39 & \\
1.5 & 0.47 & 0.08 \\
2.0 & 0.60 & 0.09 \\
3.0 & 0.41 & 0.08 \\
Thursday in a steady state week: & 0.50 & 0.08 \\
1.5 & 0.62 & 0.09 \\
2.0 & 0.07 \\
3.0 & \\
ॠMaximum 1 h TWA value of chlorobenzene concentration in \\
blood.
\end{tabular}

Table 6 Effect of variation of airborne chlorobenzene in exposure on TOTCC

\begin{tabular}{lll}
\hline & \multicolumn{2}{l}{ TOTCC (mg) } \\
\cline { 2 - 3 } Airborne exposure (GSD) & Mean & $C V$ \\
\hline 1.5 & 82.9 & $>0.01$ \\
2.0 & 82.9 & $>0.01$ \\
3.0 & 82.9 & $>0.01$ \\
\hline
\end{tabular}

affected by a change in the permutation of CBAs.

Table 5 lists the means and $\mathrm{CVs}$ of CBBmax. The means of CBBmax increased from 0.39 to $0.60 \mathrm{mg} / \mathrm{l}$ with an increase in the GSD of CBAs on the first day of exposure. The CVs were 0.08 to 0.09 , so that the CBBmax value in each trial was affected to a certain extent by a change in the permutation of CBAs. Similar tendencies were found in CBBmax on Thursday in a steady state week.

EFFECT OF AIRBORNE EXPOSURE VARIATION ON CONCENTRATIONS OF URINARY METABOLITES

Table 6 shows the simulated results of TOTCC. The means of TOTCC were 82.9 mg with CVs of $<0.01$, which suggest that TOTCC did not vary with changes in both GSD and the permutation of CBAs.

Table 7 shows the simulated results of CC (4-8), CC (6-8), and $\operatorname{CC}(22-24)$ on the first day of exposure and on Thursday in a steady state week. The means of CC(4-8), $\mathrm{CC}(6-8)$, and $\mathrm{CC}(22-24)$ were $89 \cdot 0-89 \cdot 7$, $102-103$, and $6 \cdot 1 \mathrm{mg} / \mathrm{g}$ creatinine on the first day, and 101-102, 114-115, and $12.8 \mathrm{mg} / \mathrm{g}$ creatinine on Thursday in a steady state week. Consequently, these mean values almost

Table 7 Effect of variation of exposure to airborne chlorobenzene on urinary 4-CC concentration

\begin{tabular}{|c|c|c|c|c|c|c|}
\hline \multirow[b]{3}{*}{ Airborne exposure (GSD) } & \multicolumn{6}{|c|}{ Uninary 4-CC concentration ( $\mathrm{mg} / \mathrm{g}$ creatinine) } \\
\hline & \multicolumn{2}{|c|}{$C C(4-8)$} & \multicolumn{2}{|c|}{$C C(6-8)$} & \multicolumn{2}{|c|}{$C C(22-24)$} \\
\hline & Mean & $C V$ & Mean & $C V$ & Mean & $C V$ \\
\hline $\begin{array}{l}\text { First exposure day: } \\
\quad 1.5 \\
2.0 \\
3.0\end{array}$ & $\begin{array}{l}89 \cdot 0 \\
89 \cdot 4 \\
89 \cdot 7\end{array}$ & $\begin{array}{l}0.07 \\
0.11 \\
0.17\end{array}$ & $\begin{array}{l}102 \\
102 \\
103\end{array}$ & $\begin{array}{l}0.07 \\
0.12 \\
0.18\end{array}$ & $\begin{array}{l}6 \cdot 1 \\
6 \cdot 1 \\
6 \cdot 1\end{array}$ & $\begin{array}{l}0.03 \\
0.05 \\
0.08\end{array}$ \\
\hline $\begin{array}{l}\text { Thursday in a steady state } \\
1.5 \\
2.0 \\
3.0\end{array}$ & $\begin{array}{l}\text { eek: } \\
101 \\
101 \\
102\end{array}$ & $\begin{array}{l}0.06 \\
0 \cdot 10 \\
0 \cdot 15\end{array}$ & $\begin{array}{l}114 \\
114 \\
115\end{array}$ & $\begin{array}{l}0.06 \\
0.10 \\
0.16\end{array}$ & $\begin{array}{l}12 \cdot 8 \\
12 \cdot 8 \\
12 \cdot 8\end{array}$ & $\begin{array}{l}0.02 \\
0.03 \\
0.04\end{array}$ \\
\hline
\end{tabular}

never varied, regardless of any changes in the GSD of CBAs. The $\mathrm{CC}(4-8)$ and $\mathrm{CC}(6-8)$ values in each trial were affected to a certain extent by changes in the permutation of CBAs, especially in the case with the largest GSD, because the CVs ranged from 0.06 to $0 \cdot 18$. The relation found between these urinary 4-CC concentrations and the variation in seven CBAs was that when the CBAs at the start and end of the shift were low and the CBAs in the middle of the shift were high, the $\mathrm{CC}(4-8)$ and $\mathrm{CC}(6-8)$ were the largest. Inversely, when the CBAs at the start and end of shift were high and the CBAs in the middle of shift were low, the $\mathrm{CC}(4-8)$ and $\mathrm{CC}(6-8)$ were the smallest. On the other hand, the CVs of $\mathrm{CC}(22-24)$ were $0.02-0.08$, which were less than those of $\mathrm{CC}(4-8)$ and $\mathrm{CC}(6-8)$. Consequently, the effect of the permutation of CBAs on CC(22-24) was low.

The means on Thursday in a steady state week increased by $13 \%$ of the means on the first day of exposure for CC(4-8), by $12 \%$ for CC $(6-8)$, and by $110 \%$ for $\mathrm{CC}(22-24)$. This finding suggests that the $\mathrm{CC}(22-24)$ value is greatly influenced by the previous exposures in comparison with $\mathrm{CC}(4-8)$ and $\mathrm{CC}(6-8)$.

\section{Discussion}

A physiologically based pharmacokinetic model that consisted of five tissue groups was used in general to describe uptake, distribution, metabolism, and elimination of organic solvents in the human body. ${ }^{913}$ The metabolic rate for chlorobenzene was assumed to be of the first order in our model. The simulations in this paper were not of high exposure, because the daily average CBAs was $10 \mathrm{ppm}$ and the maximum CBA was $31 \cdot 1 \mathrm{ppm}$. The maximum one-hour TWA value of chlorobenzene concentration in the liver from all 1200 trials was $0.46 \mathrm{mg} / \mathrm{l}$, so that the chlorobenzene concentration in venous blood leaving the liver was $<0.13 \mathrm{mg} / 1$. Koizumi estimated the Michaelis constants $(\mathrm{Km})$ for trichloroethylene to be $2.5 \mathrm{mg} / \mathrm{l}$ and for tetrachloroethylene to be $1.0 \mathrm{mg} / 1$ in humans. ${ }^{8}$ The $\mathrm{Km}$ value for styrene was shown to be $0.36 \mathrm{mg} / 1$ and for $\mathrm{n}$-hexane $0.58 \mathrm{mg} / \mathrm{l}^{12}{ }^{13}$ If the $\mathrm{Km}$ value for chlorobenzene is similar to that for these organic solvents, the metabolic rate is considered to be roughly of the first order in our exposure scenarios, because the chlorobenzene concentration in venous blood leaving the liver was much less than the $\mathrm{Km}$ value.

The urinary metabolites of chlorobenzene are 4-CC, $o-, m$ - and p-chlorophenols, and 4-chlorophenylmercapturic acid. The amount of 4-chlorophenylmercapturic acid is negligible. Ogata et al reported that the proportion (as chlorobenzene) of urinary 4-CC in the total amount of the four urinary metabolites was $64 \%{ }^{4}$ When that proportion was applied in our model the excretion ratio of 4-CC to the total amount of chlorobenzene that passed through the lungs was $48 \cdot 2 \%$, which was considerably different from the value $(26.5 \%)$ obtained experimentally. Consequently, 
assuming that unknown metabolites exist, the proportion of 4-CC in the total amount of all metabolites was determined to be $35 \%$ in our model. When this proportion was applied, the simulated excretion ratio $(26.5 \%)$ was equal to the observed ratio.

The simulated results were in good agreement with the experimental data. For worker B in the field survey, the simulated values were about half of the observed values in urine collected at 1030 on the two days. Because chlorobenzene exposure was measured as a one-hour time weighted average, the exposure concentration was assumed to be constant for one hour in the simulation. In general, exposure concentration, however, varies from minute to minute in workplaces. If worker B was exposed at a higher level from 1000 to 1030 and at a lower level from 1030 to 1100 , the discrepancy between the simulated and observed values can be explained. In the last half of the exposure period of the field survey, the simulated results were in good agreement with the observed values. Consequently, our model is considered to be able to describe the kinetic behaviour of chlorobenzene in the human body.

Animal experimental studies have shown that chlorobenzene is toxic to the central nervous system, kidney, and liver. ${ }^{13}$ It is not clear whether the toxicity is due to the parent chemical or its metabolites, but the chlorobenzene concentration in blood may be closely related to the toxic intensity on the organs. Consequently, $\mathrm{CBBauc}$ and $\mathrm{CBBmax}$ were selected as measures of internal exposure related to the chronic and acute effects. Because our simulation showed that CBBauc was not affected by changes in GSD and variation in CBAs, it may be sufficient to control the daily average exposure to protect workers from the chronic effects of chlorobenzene exposure. For protection from the acute effects, the short term exposure must also be controlled, as the $\mathrm{CBBmax}$ varied with changes in the GSD and permutation of CBAs.

Urinary 4-CC has been shown to be a good biological exposure index in previous studies. ${ }^{407}$ The present simulation showed that the $\mathrm{CC}(4-8)$ and $\mathrm{CC}(6-8)$ did not vary with the GSD of CBAs. Although these concentrations of urinary metabolite were affected by the permutation of CBAs, the $\mathrm{CC}(4-8)$ and $\mathrm{CC}(6-8)$ were acceptable for estimating the daily average exposure, because the CVs $(0 \cdot 07-0 \cdot 18)$ were not very high. Although the effect of the GSD and permutation of CBAs on the $\mathrm{CC}(22-24)$ was low, this concentration of urinary metabolite was not acceptable for estimating the daily average exposure, because it highly reflected the exposures of the previous days.

Our study examined the effects of variation in airborne exposure on the internal exposure and concentrations of urinary metabolites. Between worker variations in hepatic and kidney functions and fat content also affect these concentrations. ${ }^{1011}$ Consequently, the CVs of these concentrations in workplaces are expected to be greater than the values shown here.

1 Dilley JV, Lewis TR. Toxic evaluation of inhalcd chlorobenzene. Toxicol Appl Pharmacol 1978;45:327.

2 Dalich GM, Larson RE. Temporal and dose-respon features of monochlorobenzenc hepatotoxicity in rat. Fundam Appi Toxicol 1985;5:105 16.

3 American Conference of Governmental Industri.. Hygienists. Documentation of the threshold limit values al i biological exposure indices, 6th ed. Vol I. Cincinna biological exposure in

4 Ogata M, Taguchi T, Hirota N, Shimada Y, Nakae S Quantitation of urinary chlorobenzene metabolites by HPLC: concentration of 4-chlorocatechol and chlor:phenols in urine and of chlorobenzene in biologic specimens of subjects exposed to chlorobenzene. 1: Arch Occup Environ Health 1991;63:121-8.

5 Ogata $M$, Shimada $Y$. Differences in urinary monochlorobenzene metabolites between rats and humans. $I "$ Arch Occup Environ Health 1983;53:51-7.

6 Yoshida M, Sunaga M, Hara I. Urinary metabolite leveis in workers exposed to chlorobenzene. Ind Health 1986; 24: $255-8$.

7 Kumagai S, Matsunaga I. Concentrations of urinary metabolites in workers exposed to monochlorobenzere and variation in the concentration during a workshitt. Occup Environ Med 1994;51:120-4.

8 Koizumi a Potential of physiologically based pharmaci. kinetics to amalgamate kinetic data of trichloroethylene kinetics to amalgamate kinetic data of trichloroethylene and tetrachloroethylene obtaind

9 Droz PO, Guillemin MP. Human styrene exposure. (V) Development of a model for biological monitorin Int Arch Occup Environ Health 1983;53:19-36.

10 Droz PO, Wu MM, Cumberland WG, Berode $M$ Variability in biological monitoring of solvent exposur (1) Development of a population physiological mod Br f Ind Med 1989;46:447-60

11 Droz PO, W'u MM, Cumberland WG. Variability in bi logical monitoring of organic solvent exposure. (Ii) Application of a population physiological model. $\mathrm{Br} .7$ Ind Med 1989;46:547-58.

12 Ramsey JC, Andersen ME. A physiologically based description of the inhalation pharmacokinetics of styrene in rats and humans. Toxicol Appl Pharmacol 1984;73: in rats and $159-75$.

13 Perbellini I, Mozzo P, Olivato D, Brugnone I: "Dynamic" biological exposure indexes for n-hexane and 2,5-hexanedione, suggested by a physiologically. and 2, 5-hexanedione, suggested by a physiologically based pharmacokin

14 Fernandez JG, Droz PO, Humbert BE, Caperos JR. Trichloroethylene exposure simulation of uptake, excr:tion, and metabolism using a mathematical model. $\mathrm{Br} F$ Ind Med 1977;34:43-55.

15 Fiserova-Bergerova V, Vlach J, Singhal K. Simulation and prediction of uptake, distribution, and exhalation of organic solvents. Br F Ind Med 1974;31:45-52.

16 Fiserova-Bergerova $V$, Hughes $\mathrm{HC}$. Species differences $v: 3$ bioavailability of inhaled vapors and gases. In: FiserovaBergerova V, ed. Modeling of inhalation exposure 10 zapo uptake, distribution, and slimination, Vol 2 Boca Raton: CRC Press, 1983:97-106.

17 Fiserova-Bergerova V. Gases and their solubility: a review of fundamentals. In: Fiserova-Bergerova V, ed. Modcling of inhalation exposure to vapors: uptake, distribution, and of inhalation exposure to vapors: uptake, distribution, an.

18 Guyton AC. Measurement of the respiratory volumes of laboratory animals. Am 7 Physiol 1947;150:70-7.

19 Stahl WR. Scaling of respiratory variables in mammal. f Appl Physiol 1967;22:453-60.

20 Astrand I. Effect of physical exercise on uptakc, distribution and elimination of vapors in man. $I_{n}$ : Fiserova-Bergerova V, ed. Modeling of inhalatw" exposure to vapors: uptake, distribution, and elimination. Vol 2. Boca Raton: CRC Press 1983:107 30

21 Pang KS, Rowland M. Hepatic clearance of drugs: theoretical considerations of a "well-stirred" model an 1 a "parallel tube" model. I Phamacokinet Biopham 1977;5:625-53.

22 Sullivan TM, Born GS, Carlson GP, Kessler WV. The pharmacokinetics of inhaled chlorobenzene in the rat. Toxicol Appl Pharmacol 1983;71:194-203.

23 Yamaoka K. Pharnacokinetic evaluation using micr computer. Kyoto: Nankodo 1984:63-9 (in Japanese).

24 Yamada S, Baba Y. Assessment of physical activity $1 \mathrm{y}$ means of a caloric counter combined with an acceleromeans of a caloric counter combined with an accelerometer. Fapanese foumal of Industrial Heal
$1990 ; 32: 2537$ (in Japanese with English abstract).

25 Kumagai S, Matsunaga I. Changes in the distribution (f short-term exposure concentration with different averaging times. Am Ind Hyg Assoc $\tilde{f}$ (in press) 